\title{
REVISANDO A TEORIA DAS RELAÇÕES INTERNACIONAIS. ENFOQUE IMPERIAL: O SURGIMENTO DE UMA NOVA TEORIA?
}

\author{
${\text { Gustavo Javier Castro Silva }{ }^{*} \text { e Alejandro Gabriel Olivieri** }}^{* *}$
}

\begin{abstract}
Resumo: O presente ensaio tem como objetivo discutir as principais características da denominada "Teoria Imperial ou Império", fundamentada no trabalho conjunto de Tony Negri e Michael Hardt. O trabalho se divide em três partes. Na Introdução, expõem-se as principais idéias a serem desenvolvidas no ensaio. Na segunda parte, faz-se uma avalição suscinta das principais características da "sociedade global", enfatizandose seu caráter contraditório e suas múltiplas dimensões. Na terceira parte, explicam-se as principais características da Teoria Imperial e sua contribuição para o desenvolvimento teórico de novas abordagens no quadro da Teoria das Relações Internacionais.
\end{abstract}

\section{INTRODUÇÃO}

O presente trabalho nasce do nosso interesse pela teoria ${ }^{1}$ no âmbito das ciências sociais, insere-se no contexto da história das idéias e, mais especificamente, no campo da Teoria das Relações Internacionais. A nossa atividade docente e de pesquisa e as inúmeras leituras feitas, levaram-nos a constatar a confusão, as lacunas e os debates, que têm afetado e continuam afetando, no âmbito da teoria, a disciplina das relações internacionais ${ }^{2}$. Nossa formação filosófica universitária ajudou no surgimento deste interesse, tanto quanto a nossa

\footnotetext{
* Licenciado em Filosofia - Universidad Catolica de Chile; Mestre em Relações Internacionais - UnB. Coordenador de graduação do Centro Universitário UNIEURO.

** Licenciado em Filosofia - Universidad Nacional de Buenos Aires; Mestre em Sociologia - UFSC. Professor dos Cursos de Direito e de Relações Internacionais do Centro Universitário UNIEURO.

${ }^{1}$ Empregamos o conceito de teoria em seu sentido geral. Um sistema coerente de proposições sobre uma zona da realidade, quer dizer, como um conjunto de declarações sobre o real que tenta dar uma explicação de fatos determinados.

${ }^{2}$ É nossa opinião que até agora não existe um claro consenso em torno do significado do termo relações internacionais. Em princípio, usaremos este conceito como a disciplina que estuda tanto os contatos de povos e Estados através das fronteiras nacionais, quanto a complexidade das atividades transnacionais e transgovernamentais. A expressão "relações internacionais", segundo Celestino del Arenal, "abrange o conjunto das relações sociais que formam a sociedade internacional, tanto as de caráter político como as não políticas, sejam econômicas, culturais, humanitárias, religiosas etc., tanto as que se produzem entre os Estados como as que tem lugar entre outros atores da sociedade internacional e entre estes e os Estados." (Arenal, 1987: 20)
} 
percepção de que uma ciência, para afirmar-se como tal, precisa aperfeiçoar as suas bases teóricas.

Nosso trabalho tentará mostrar resumidamente como no campo do conhecimento, os paradigmas usados para a análise das relações internacionais sofrem grandes transformações, que acompanham aquelas ocorridas na realidade. Temos percebido como os acontecimentos históricos foram construindo as diferentes perspectivas teóricas nas Relações Internacionais. Mas, por outro lado, o prisma teórico daqueles que formulam a política internacional influencia nas decisões que são tomadas. Assim, a história das relações internacionais confunde-se com a história da sua teoria, num sentido dialético.

O objetivo geral do ensaio será expor, de modo preliminar e exploratório, as principais contribuições teóricas vinculadas ao surgimento de um novo enfoque teórico das relações internacionais: a Teoria Imperial. Ao reunir, analisar e interpretar informações, através da observação documental e da literatura existente sobre o assunto, apresentaremos as contribuições que consideramos relevantes da Teoria Imperial, que nos parecem mais originais, para o estudo da teoria das relações internacionais.

Por que tentar resumir as principais tendências teóricas das relações internacionais e por que relacioná-las com a Teoria Imperial? A resposta é que protagonizamos um momento histórico importante no processo de desenvolvimento das ciências em geral e das ciências sociais em particular. É um momento de transição, de esgotamento de alguns paradigmas e do surgimento de novos modelos de interpretação da realidade. É um momento de balanço sobre o que foi alcançado. Como afirma Saraiva (2001), os principais enfoques teóricos nas relações internacionais ficaram petrificados ante as mudanças globais ocorridas nas últimas décadas. Desta maneira, para que a história dos acontecimentos ${ }^{3}$ adquira um pleno sentido é necessário iluminá-la a partir de fundamentos teóricos claros e sólidos. É este o aspecto que torna relevante o tema a ser desenvolvido neste trabalho.

Em síntese, ao revisar as principais teorias das relações internacionais e os debates nelas travados, pode-se considerar a Teoria Imperial como um novo paradigma para explicar as relações internacionais, no sentido de que, por um lado, não se identifica totalmente com algumas das teorias nas relações internacionais, entretanto absorve

\footnotetext{
${ }^{3}$ Sobre o conceito de "história dos acontecimentos" ver: Jean-Baptiste Duroselle. Todo Império Perecerá. Teoria das relações Internacionais. Brasília: Editora Universidade de Brasília; São Paulo: Imprensa Oficial do Estado, 2000.
} 
elementos de cada uma delas; e, por outro lado, a Teoria Imperial traz uma contribuição original à teoria das relações internacionais. Aliás, somente o tempo pode dizer se esta contribuição não somente será original, como também, efetiva.

\section{Complexidade e Paradoxalidade da Sociedade Global}

Deseja-se estabelecer como ponto de partida - pressupostos centrais das análises a serem realizadas - as seguintes afirmações: há, na atualidade, muitas evidências no que diz respeito à existência de uma densa materialidade dos processos de globalização. As características mais visíveis da globalização - compactação espacial, aceleração temporal e produção de novas heterogeneidades - se produzem em -e dão origem a - contextos socionaturais de alta incerteza. Portanto, seus diversos vetores são contraditórios e abertos a vários desdobramentos (às vezes conflitantes entre eles mesmos). Acrescenta-se que, como decorrência desse estado de coisas, a proposta epistemológica que percorre este trabalho baseia-se em três postulados que nortearão as análises: complexidade, paradoxalidade e contraditoriedade da realidade contemporânea (Viola e Olivieri, 1997).

Pode-se caracterizar o sistema atual como um capitalismo da informação globalizada. A sociedade capitalista de informação globalizada difere essencialmente de sua antecessora, a sociedade capitalista industrial. O componente que caracteriza a sociedade capitalista da informação globalizada é o conhecimento intensivo, ou seja, a informação e o conhecimento comandam o processo produtivo e a tomada de decisão. Com efeito, na sociedade capitalista de informação globalizada existe um aumento da forma simbólica do trabalho em detrimento da material (típica do capitalismo industrial) e, por esse motivo, adquirem cada vez mais importância e valor os produtores simbólicos. No entanto, esse fato tem um desdobramento contraditório: por um lado, existe uma agregação exponencial de símbolos, que gera a possibilidade de uma apropriação inteligente e criativa desse universo simbólico pelas pessoas visando ao seu desenvolvimento pessoal e social, mas, por outro, muita dessa agregação simbólica também pode ser manipulatória, trabalhando com o engano e a ilusão (ex. certas formas de publicidade e a manipulação de símbolos monetários nos mercados financeiros). Por tal motivo, um aspecto relevante a ser

desenvolvido neste capitalismo é a produção de símbolos com alto componente de conhecimento, de autoconhecimento e de formas estéticas. Em síntese, o capitalismo 
globalizado informatizado é o sistema social de escala planetária da década de 1990 que, depois do colapso do comunismo, subordina outros subsistemas sociais ainda existentes (sociedades tribais, sociedades camponesas, sociedades industriais atrasadas e sociedades socialistas de mercado).

O impacto mais imediato da globalização, no senso comum e no cotidiano de todos nós, está na percepção, mais consciente e acurada, de que nos encontramos fortemente inseridos -e tentando encaminhar nossas vidas - num período histórico caracterizado por profundas transformações estruturais nos pressupostos, critérios e certezas básicas, a partir das quais organizamos nossa existência individual e coletiva para agir no mundo, visando à construção da nossa subjetividade individual e coletiva num processo de interação complexa com os sistemas sociais e naturais que conformam o Planeta Terra.

As Ciências Sociais têm mostrado, ao longo de sua história, que a construção da subjetividade está ancorada em algumas certezas e em certa segurança; enfim, em certos parâmetros que guiem tanto a ação individual como a coletiva. No entanto, o dilema que apresenta, na atualidade, precisamente por viver e agir em condições de globalização intensivas para compreender, em profundidade, as complexas dinâmicas mundiais e, portanto, tampouco para guiar, normativamente, as ações individuais e coletivas dos seres humanos no contexto dessas tendências globais. Assim, na atualidade, a constituição de sujeitos empreendedores e responsáveis, com capacidade de lidar precisamente com estes novos desafios, implica o desenvolvimento de um questionamento sistemático - e reflexivamente monitorado - de nossas certezas mais íntimas acerca de nós mesmos enquanto sujeitos, dos outros sujeitos e do mundo social e natural ao nosso redor.

Em suma, constitui-se numa temática de constante reflexão consciente (tanto pessoal como social) que diz respeito às diversas maneiras através das quais nos vamos tornando sujeitos, num mundo em constante turbilhão. Essa condição tem se caracterizado com a metáfora da "turbulência", para se dar a entender a dificuldade, a instabilidade e a carência de um controle total, por parte dos próprios atores, das inúmeras variáveis que, em diversos graus, influenciam a constituição de nossa própria condição existencial na situação presente. Esses processos questionam muitas das nossas crenças básicas mais arraigadas no que diz respeito àquilo que é (e deveria ser) o mundo natural e social, as relações sociais (trabalho, profissões, etc.), as relações pessoais ligadas à intimidade (a amizade, o amor, a 
sexualidade, etc.) e, em decorrência disso, em relação à nossa concepção do Eu íntimo; quer dizer, quais os critérios aceitos para guiar a nossa individualização e subjetividade visando à constituição da intimidade pessoal em condições de globalização (Olivieri, 2000).

Em primeiro lugar, a globalização traz consigo diversos desafios, tanto no nível pessoal quanto no profissional, Viver em condições de globalização intensiva-acelerada nos desafia para tentar compreender e interpretar estas mudanças turbulentas, seja para nos posicionarmos criticamente (quer dizer, reflexivamente) frente aos processos em curso, seja para podermos interferir, autoconsciente e eficientemente, sobre eles. Em segundo lugar, os mesmos processos desencadeados pela globalização geram um profundo sentimento de angústia pessoal e, em diversos graus, de desestruturação social pela velocidade, profundidade e amplitude das mudanças em curso.

Esta experiência quotidiana angustiante, ao se relacionar estreitamente com uma forte sensação de insegurança frente à possibilidade, sempre latente, de "ficar por fora" das transformações presentes, tem um impacto direto sobre a própria autopercepção, gerando, em alguns casos, uma baixa auto-estima pessoal. Tal déficit na auto-estima, numa espécie de feed-back vicioso, retro-alimenta a angústia e a insegurança, na medida em que gera uma autopercepção que se resume num "não estar preparado". Por último, essa "falta de preparação" relaciona-se com a carência e/ou não atingimento dos pré-requisitos intelectuais-afetivos necessários que requerem estas mudanças, para poder "processar" e dar conta do complexo conjunto de atitudes e capacidades (pessoais e profissionais) que demandam estes mesmos fenômenos em curso.

Com efeito, experimentamos, às vezes em forma angustiante, que a globalização implica uma demanda exagerada de nossas próprias capacidades (intelectuais-emocionais), talvez como poucas vezes aconteceu em outros períodos históricos (sobretudo no que diz respeito a sua amplitude e profundidade para enfrentar estes desafios). Esta redefinição radical complexa de nosso "estar no mundo" pode ser explicada, em grande parte, pela extensividade e intensividade desses processos. Por esse mesmo motivo, a globalização exige (e faz possível) uma revolução em nossas capacidades e destrezas para lidar com suas diversas dimensões.

Portanto, uma abordagem complexa -menos linear e homogênea - dos processos de globalização que estão modelando os acontecimentos contemporâneos, quer dizer, uma 
análise que assinale, ao mesmo tempo, os matizes, os diversos pontos de conflito e os dilemas imbricados nesses fenômenos deveria ter, ao menos, as seguintes características:

1) Uma aproximação global aos vastos e complexos problemas de um mundo no qual está crescendo aceleradamente a interdependência complexa assimétrica entre as nações dentro de um único sistema planetário (global sistem).

2) Uma focalização da atenção sobre temas, políticas e opções com uma perspectiva de mais longo prazo daquela que podem dar conta os governos, os quais respondem, na maioria das vezes, às preocupações mais imediatas (e, também, particularistas) de eleitores insuficientemente informados sobre as próprias políticas em jogo, desconsiderando, portanto, nas suas decisões políticas, lógicas mais universalistas que visem a defender o bem público.

3) Uma compreensão mais precisa e aprofundada das interações e inter-relações no marco do sistema global, as quais muitas vezes acontecem "relacionando" espaços geográficos e geo-econômicos localizados a longas distâncias, visando a um entendimento mais idôneo do emaranhado dos problemas contemporâneos.

4) Uma ação conjunta, compreensiva e simultânea destinada a resolver o maior número possível de fatores dessa "problemática global" - como a denominou o Clube de Roma - ou, ao menos, balizar algumas das vias que possam conduzir a soluções e estratégias mais eficazes. Isso significa encarar uma análise sistemática e uma ação simultânea sobre seus elementos principais, prestando uma especial e detida atenção ao efeito recíproco de cada um deles.

Em suma, a humanidade parece encontrar-se atenazada por uma finisecular atitude de incerteza no umbral do novo século; a finalização de um milênio, porém, pode aportar ainda uma mística mais profunda apesar de estendida carga de complexidade, rápida mudança e incerteza que traz consigo. Um primeiro corolário das transformações atuais assinala que o fim da Guerra Fria - e da tensão Este-Oeste (EE.UU. e URSS) - faz reemergir uma série de conflitos até então ocultos, permitindo que aspirações, reprimidas por longo tempo, se expressarem em alguns casos violentamente, assumindo, pateticamente, nos casos mais extremos, a lógica dos conflitos tribais.

As diferenças econômicas mundiais, as escandalosas desigualdades sociais, e a vasta e extrema pobreza, refletidas inversamente - como num espelho cínico - num excesso 
de riqueza, consumo e desinteresse, produzem toda classe de tensões e conflitos que vão aparecendo e ressurgindo pelas mais diversas zonas geográficas. As brutais mudanças atuais, que estão ocorrendo simultaneamente tanto nas regiões ricas quanto nas mais pobres do Planeta, produzem, à primeira vista, uma situação paradoxal - mas que exprime muito bem a complexidade dos processos de globalização em curso e constitui-se num emblema desta "primeira revolução global" -: a existência, tensa e persistente, de um mundo rico "dentro" do mundo pobre e de um mundo pobre "dentro" do mundo rico.

\section{CLASSIFICAÇÃO PRELIMINAR DOS PRINCIPAIS ENFOQUES TEÓRICOS NAS RELAÇÕES INTERNACIONAIS}

O seguinte esquema apresenta uma classificação prévia, apenas com uma finalidade pedagógica, dos diferentes enfoques teóricos das relações Internacionais e o lugar que nele ocupa a Teoria Imperial.

\section{DEBATES DOMINANTES}

1. REALISTAS VERSUS IDEALISTAS

2. TRADICIONALISTAS VERSUS BEHAVIORISTAS

3. GLOBALISTAS VERSUS NEO-REALISTAS

\section{A VISÃO MARXISTA}

1. A TEORIA DO IMPERIALISMO

2. A TEORIA DA DEPENDÊNCIA

\section{TEORIAS DE ALCANCE MÉDIO}

1. TEORIAS DO CONFLITO

2. TEORIAS DA INTEGRAÇÃO

3. TEORIA DA TOMADA DAS DECISÕES

\section{TEORIAS ALTERNATIVAS}

1. A PESQUISA PARA A PAZ 


\section{A TEORIA IMPERIAL}

\section{OUTRAS}

Chamamos de debates dominantes às discussões ocorridas entre enfoques teóricos que surgem e se desenvolvem em países que ocupam um lugar preponderante na hierarquia internacional. Basicamente, estamos falando de teorias elaboradas por autores americanos e britânicos.

Dentro da perspectiva marxista das relações internacionais destacamos a Teoria Imperialista e a Teoria da Dependência. Ao analisar estas duas teorias será necessário identificar as diferentes vertentes que encontramos em cada uma delas. Inclusive, no caso específico da teoria da dependência, as correntes não marxistas dentro dela.

Denominamos de teorias de alcance médio os enfoques teóricos que não tentam uma explicação abrangente da realidade internacional, mas sim a análise de fenômenos específicos como o conflito, os processos de integração e o processo de tomada das decisões.

Por último, identificamos algumas teorias que denominamos de alternativas, basicamente por três razões. Em primeiro lugar, por não serem teorias surgidas especificamente dentro das relações internacionais, mas sim construídas no âmbito mais amplo da filosofia e das ciências sociais. Em segundo lugar, essas teorias formulam concepções críticas aos enfoques teóricos dominantes. E, em terceiro lugar, também são alternativas por não se consolidarem dentro do ambiente acadêmico das relações internacionais. Em princípio destacamos duas teorias alternativas. A primeira é a Pesquisa para a Paz e a segunda teoria alternativa é a Teoria Imperial, nome com o qual designamos as idéias de dois autores, Michael Hardt ${ }^{4}$ e Antonio Negri ${ }^{5}$, vertidas no livro Império $^{6}$.

\footnotetext{
${ }^{4}$ Michael Hardt é Doutor em Literatura Comparada e professor da Duke University (uma das universidades norte-americanas orientadas para o desenvolvimento dos estudos culturais).

${ }^{5}$ Antonio Negri é um antigo dirigente histórico do grupo Pottere Operario. Atualmente Negri cumpre, no cárcere de Rebibbia (Roma), uma pena de trinta anos de prisão por "insurreição armada contra o Estado" e de quatro anos e meio por "responsabilidade moral" nos confrontos entre militantes e a polícia em Milão, entre 1973 e 1977. Ele tem direito a sair durante o dia. No seu exílio de quatorze anos em Paris (antes do seu ingresso na prisão), foi professor na Escola Normal Superior e professor na Universidade Paris VIII, assim como no Colégio Internacional de Filosofia.
} 


\section{A TEORIA IMPERIAL: UMA INTERPRETAÇÃO PRELIMINAR}

Provavelmente pode-se afirmar que Império seja o êxito editorial mais estranho das últimas décadas nos Estados Unidos. Já resulta extraordinário que este livro, escrito por um jovem professor da Universidade de Duke (Michael Hardt) e um pensador marxista, criminalizado e quase apagado do horizonte acadêmico italiano (Antonio Negri), tenha sido qualificado pelo jornal New York Times como o mais importante da última década. O esgotamento imediato da primeira edição, as traduções a mais de dez idiomas, os milhares de exemplares que circulam pelas universidades norte-americanas, as capas dedicadas dos suplementos culturais dos principais jornais do mundo, as inúmeras entrevistas aos seus autores, o profuso material na Internet, nos demonstram a necessidade de pensar no êxito de Império.

Em Império os seus autores afirmam a necessidade de fugir da velha concepção marxista-leninista conforme a qual o imperialismo é a expansão do capitalismo nacional em direção a espaços mundiais, criando uma hierarquia através da centralidade das grandes potências. Hoje esta afirmação não faz sentido dado que o Estado-nação já não é mais o sujeito do desenvolvimento capitalista mundial. O mercado mundial é uma realidade na qual as nações vão diluir-se. Hardt e Negri não querem afirmar com isto que o Estadonação tenha deixado de existir, mas que se está produzindo uma transferência essencial da sua soberania. Este ponto tem-se tornado uma das questões mais polêmicas no âmbito das relações internacionais nos últimos anos.

Assim, parece não existir um lugar de centralização do império, de maneira que se faz necessário falar de um "não lugar". A questão essencial consiste na forma como se processa o "mando" e não o lugar desde onde este é exercido. Em outras palavras, por um lado, Hardt e Negri afirmam que não há um "fora" do "Império" e, por outro lado, a idéia de que o Império não é os Estados Unidos. A tentativa de construção de um espaço exterior ao Império resulta numa impossibilidade dado que isto implicaria numa certa autonomia dos Estados-nação, autonomia que hoje se vê ameaçada em função de complexos equilíbrios do sistema financeiro mundial.

\footnotetext{
${ }^{6}$ Michael Hardt e Antonio Negri. Império. Rio de Janeiro: Record, 2001.
} 
Mas, ocupar um lugar fora do Império não é a única possibilidade de uma prática política. Os autores em questão pensam na possibilidade de construir no interior do Império uma alternativa que não seja nem regional nem nacional, formada por aquilo que eles denominam de "subjetividades transversais". Desta maneira, uma reforma local é utópica e impossível.

É importante destacar que o termo "Império" não é usado como uma metáfora, dado que isto exigiria uma demonstração das semelhanças entre a ordem mundial na atualidade e os Impérios de Roma, China, das Américas, entre outros, mas como conceito, o que pede basicamente uma abordagem teórica.

Neste sentido podemos mencionar quatro características essenciais do Império:

1. O Império caracteriza-se pela ausência de fronteiras: o poder exercido pelo Império não tem limites. Trata-se de um regime que abrange a totalidade do espaço, ou que de fato governa todo o mundo "civilizado". Não existem fronteiras territoriais confinando o poder do Império.

2. O conceito de Império apresenta-se não como um regime histórico nascido da conquista, e sim como uma ordem que na realidade suspende a história e dessa forma determina, pela eternidade, o estado de coisas existente. Em outras palavras, o Império apresenta-se no seu modo de governo como um regime sem fronteiras temporais, e, neste sentido, fora da História ou no fim da História.

3. O Império não só administra um território com sua população mas também cria o próprio mundo que ele habita. Não apenas regula as interações humanas como procura reger diretamente a natureza humana. O poder de mando do Império funciona em todos os registros da ordem social, descendo às profundezas do mundo social.

4. Apesar da prática do Império banhar-se continuamente em sangue, o conceito de Império é sempre dedicado à paz - uma paz perpétua e universal fora da História.

Por último, a transição para o Império e seus processos de globalização oferece novas possibilidades para as forças de libertação. "As forças criadoras da multidão que sustenta o Império são capazes também de construir, independentemente, um Contraimpério, uma organização política alternativa de fluxos e intercâmbios globais"”. Essas

${ }^{7}$ Hardt e Negri, op. cit, p. 15. 
forças que contestam o Império e prefiguram uma sociedade global alternativa não estão, elas próprias, limitadas a qualquer região geográfica.

\section{BIBLIOGRAFIA}

ALMEIDA, Paulo Roberto de. Relações Internacionais e Política Externa do Brasil: Dos Descobrimentos à Globalização. Porto Alegre: Ed. da Universidade/UFRGS, 1998.

BRAILlARD, Philippe e SENARCLENS, Pierre. El Imperialismo. México: Fondo de Cultura Económica, 1980.

BURTON, J.W. Teoría de las Relaciones Internacionales. México: Universidad Nacional Autónoma de México, 1986.

CARR, Edward H. Vinte Anos de Crise: 1919-1939. Uma Introdução ao Estudo das Relações Internacionais. Brasília: Editora Universidade de Brasília, Instituto de pesquisa de Relações Internacionais; São Paulo: Imprensa Oficial do Estado de São Paulo, 2001.

CASTRO, Gustavo. A Teoria das Relações Internacionais e a Pesquisa para a Paz. Brasília: Royal Court/CEUB, 1997.

CERVO, Amado Luiz. Relações Internacionais da América Latina: Velhos e Novos Paradigmas. Brasília: IBRI, 2001.

CHOMSKY, Noam. 11 de Setembro. Rio de Janeiro: Bertrand Brasil, 2002.

DUROSELLE, Jean-Baptiste. Todo Império Perecerá. Brasília: Editora Universidade de Brasília; São Paulo: Imprensa Oficial do Estado, 2000.

.HALliDAY, Fred. Repensando as Relações Internacionais. Porto Alegre: Ed. da Universidade/UFRGS, 1999.

HARDT, Michael e NEGRI, Antonio. Império. Rio de Janeiro: Record, 2001.

MENA, Carlos Eduardo. Toma de Decisiones y Políticas. Buenos Aires: GEL, 1989.

MORGENTHAU, Hans. Escritos sobre Política Internacional. Madrid: Editorial Tecnos, 1990.

MUNOZ, Heraldo. A Nova Política Internacional. São Paulo: Editora Alfa Omega, 1996. 
OLIVIERI, A. e VIOLA, E. Globalização, Sustentabilidade e Governabilidade Democrática no Brasil. In: TRINDADE, Antônio Augusto Cançado e CASTRO, Marcus Faro de (Orgs.). A Sociedade democrática no final de século. Brasília: Paralelo 15, 1997.

OLIVIERI, A. Os dilemas ético-políticos da crise ambiental global: O ambientalismo multissetorial e o desenvolvimento sustentável. In: Revista Ethos. Brasília: CEPEB, 2000.

PEREIRA, Juan Carlos. Historia de las Relaciones Internacionales Contemporáneas. Barcelona: Ed. Ariel, 2001.

SARAIVA, José Flávio Sombra (Org.) Relações Internacionais - Dois Séculos de História:

Entre a Preponderância Européia e a Emergência Americano-Soviética (1815 - 1947). Brasília: IBRI, 2001.

SARAIVA, José Flávio Sombra (Org.) Relações Internacionais - Dois Séculos de História: Entre a Ordem Bipolar e o Policentrismo (de 1947 a nossos dias). Brasília: IBRI, 2001. TOMASSINI, Luciano. Teoría y Práctica de la Política Internacional. Santiago: Ediciones Universidad Católica de Chile, 1989. 